\title{
Potato-Infecting Ralstonia solanacearum Strains in Iran Expand Knowledge on the Global Diversity of Brown Rot Ecotype of the Pathogen
}

\author{
Nasim Sedighian, ${ }^{1}$ S. Mohsen Taghavi, ${ }^{1}$ Habiballah Hamzehzarghani, ${ }^{1}$ Jan M. van der Wolf, ${ }^{2}$ \\ Emmanuel Wicker, 3,4 and Ebrahim Osdaghi $1, \dagger$ \\ ${ }^{1}$ Department of Plant Protection, College of Agriculture, Shiraz University, Shiraz 71441-65186, Iran \\ ${ }^{2}$ Wageningen University and Research, Business Unit Biointeractions and Plant Health, 6700 AA, Wageningen, The Netherlands \\ ${ }^{3}$ IPME, Univ Montpellier, CIRAD, IRD, Montpellier, France \\ ${ }^{4}$ CIRAD, UMR IPME, Montpellier, France \\ Accepted for publication 11 May 2020.
}

ABSTRACT

\begin{abstract}
Bacterial wilt and brown rot disease caused by Ralstonia solanacearum species complex (RSSC) is one of the major constraints of potato (Solanum tuberosum) production around the globe. During 2017 to 2018, an extensive field survey was conducted in six potato-growing provinces of Iran to monitor the status of bacterial wilt disease. Pathogenicity and host range assays using 59 bacterial strains isolated in Iran showed that they were pathogenic on eggplant, red nightshade, pepper, potato and tomato, while nonpathogenic on common bean, cowpea, cucumber, sunflower, zinnia and zucchini. PCR-based diagnosis revealed that the strains belong to the phylotype IIB/sequevar 1 (IIB/I) lineage of the RSSC. Furthermore, a fivegene multilocus sequence analysis and typing $(e g l, f l i C, g y r B, m u t S$, and $r p l B$ ) confirmed the phylogenetically near-homogeneous nature of the
\end{abstract}

strains within IIB/I lineage. Four sequence types were identified among 58 IIB/1 strains isolated in Iran. Phylogenetically near-homogeneous nature of the strains in Iran raise questions about the mode of inoculum entry of the bacterial wilt pathogen into the country (one-time introduction versus multiple introductions), while the geographic origin of the Iranian $R$. solanacearum strains remains undetermined. Furthermore, sequence typing showed that there were shared alleles (haplotypes) and sequence types among the strains isolated in geographically distant areas in Iran, suggesting intranational transmission of the pathogen in the country.

Keywords: bacterial wilt, bacteriology, phylotype, Ralstonia solanacearum species complex, sequevar, solanaceous crops, Solanum tuberosum
Solanaceous crops, i.e., eggplant (Solanum melongena), pepper (Capsicum spp.), potato (S. tuberosum), and tomato (S. lycopersicum), comprise a large fraction of food resources in Iran following wheat and rice (FAOSTAT 2018). Commercial production of solanaceous crops has significantly increased in the past decades, with a concomitant increase of crop loss risks due to abiotic and biotic stresses (Osdaghi et al. 2017). Aside from the diseases caused by fungi, oomycetes, and viruses, several bacterial agents have been frequently reported to infect these crops around the world (Ansari et al. 2019; Jones et al. 2016; van der Wolf and De Boer 2007; Wale et al. 2008). Accordingly, a comprehensive countrywide quarantine program was initiated in Iran from 2013 to monitor the status of bacterial diseases on solanaceous crops. As a result, the occurrence of pepper and tomato bacterial spot diseases caused by Xanthomonas euvesicatoria pv. euvesicatoria and $X$. euvesicatoria pv. perforans, respectively, was reported in the country (Osdaghi et al. 2016, 2017). Widespread distribution of Clavibacter michiganensis the causal agent of tomato bacterial canker was also reported in Iran (Osdaghi et al. 2018a).

${ }^{\dagger}$ Corresponding author: E. Osdaghi; eosdaghi@shirazu.ac.ir

Funding: Financial support was provided by Shiraz University, Shiraz, Iran.

Author contributions: E.O. and N.S. conceived and designed the study, with assistance from E.W. and S.M.T. N.S. carried out the experiments. E.O. and N.S. analyzed and interpreted the data with assistance from H.H. and E.W. N.S. and E.O. prepared the paper, with assistance from S.M.T., H.H., E.W., and J.M.W. All the coauthors revised the final manuscript and E.O. acted as the corresponding author.

*The $e$-Xtra logo stands for "electronic extra" and indicates that three supplementary figures are published online.

The author(s) declare no conflict of interest.

(C) 2020 The American Phytopathological Society
Furthermore, preliminary quarantine inspections and field surveys across potato-growing areas and potato storages around the country revealed an alarming rise in potato bacterial wilt disease incidence, although the causal agent Ralstonia solanacearum has been listed in the intranational quarantine list since 1980s (Danesh and Bahar 1984).

The $R$. solanacearum species complex (RSSC) causes bacterial wilt disease on potato and other solanaceous vegetables, i.e., eggplant, pepper, and tomato (Hayward 1994). Furthermore, the consortia of $R$. solanacearum pathogens are capable of infecting more than 450 monocot and dicot plant species in over 50 botanical families (Elphinstone 2005). The pathogen is included in the A2 (high risk) list of quarantine organisms by the European and Mediterranean Plant Protection Organization (EPPO 2018). Bacterial wilt disease was first reported in the southern United States in the late 19th century on tomato plants (Smith 1896). Infected plant materials (e.g., potato tubers) transmit the pathogen over long distances; hence, quarantine inspections and plant sanitary practices are the cornerstone of disease management (EPPO 2018).

Until recently, RSSC was subdivided into five races based on the host range of the strains, and six biovars based on the ability of the strains to use a range of carbohydrates in culture media (Buddenhagen et al. 1962; Hayward 1994). However, the race/ biovar system had a limited functional usefulness compared to the subsequently introduced molecular-phylogenetic approaches (Champoiseau et al. 2009). By the beginning of the genomic era, RSSC has been sectioned into four phylotypes (I, II, III, and IV) based on the phylogeny of the sequences of egl and $h r p B$ genes and internal transcribed spacer region, which also reflects the geographical origin of the strains (Poussier et al. 2000a, b). Additionally, each of the four phylotypes were subdivided into different sequevars using the phylogeny of $e g l$ gene sequence (Fegan and Prior 2005). Subsequently, multilocus sequence 
analysis (MLSA) and typing (MLST) using the sequences of eight chromosomal housekeeping genes ( $g a p A, g d h A, p p s A, a d K$, gyrB, $m u t S, r p l B$, and $l e u S$ ) and three megaplasmid virulence-associated genes ( $e g l, f l i C$, and $h r p B)$ confirmed the phylotype/sequevar-based taxonomy of the RSSC (Castillo and Greenberg 2007; Wicker et al. 2012). Recently, reclassification of RSSC into three species was proposed; thereby, only the phylotype II strains remained as $R$. solanacearum, while phylotype I and III strains were designated as $R$. pseudosolanacearum, and phylotype IV strains were divided into three subspecies of $R$. syzygii, i.e., $R$. syzygii subsp. syzygii, $R$. syzygii subsp. celebensis, and $R$. syzygii subsp. indonesiensis (Safni et al. 2014; Prior et al. 2016).

Although potato bacterial wilt and brown rot is more frequently caused by phylotype IIB/sequevar 1 (IIB-1) of $R$. solanacearum, potato can be infected by a large diversity of other RSSC lineages. For instance, within phylotype II, the lineages IIB-2, IIB-3, IIB-25, IIB-28, IIA-7, and IIA-35 were also reported to infect potato plants (Cellier and Prior 2010; Hong et al. 2012; Santiago et al. 2017). Recently, new sequevars within the phylotype IIB were isolated from wilting potato plants in Brazil and Peru (Gutarra et al. 2017; Santiago et al. 2017). Additionally, strains belonging to phylotypes I, III, and IV have been reported as causing potato bacterial wilt (Gurjar et al. 2015; Ravelomanantsoa et al. 2018; Sagar et al. 2014). These different points illustrate the fact that accurate characterization of potato bacterial wilt pathogen needs a series of molecularphylogenetic analyses to precisely determine the phylogenetic position and taxonomic status of potato-infecting RSSC strains in a given area.

In Iran, bacterial wilt caused by $R$. solanacearum was first reported on potato in 1984 in Isfahan province (Center) (Danesh and Bahar 1984). In the early 2000s, biovar 2T (IIB-25) strains were isolated from potato in a restricted area in temperate regions of Khuzestan province in southwestern Iran (Nouri et al. 2009). So far, identification of $R$. solanacearum in Iran has mostly relied on the symptomatology of the host plants and phenotypic characteristics of the causal agent; although biovar determination, rep-PCR-based genetic diversity, and phylotype-specific multiplex PCR were also used for characterization of the pathogen (Izadiyan and Taghavi 2011). Hence, detailed information on the geographic distribution, host range, and phylogenetic position of potato bacterial wilt pathogen in Iran is mostly lacking. Our field surveys carried out during 2017 to 2018 throughout potato-growing provinces in the country revealed the incidence of bacterial wilt in new areas with no history of the disease. Considering the economic importance of potato cultivation in Iran, a multi-phasic characterization of the causal agent is warranted to decipher the host range, phylogenetic position, and genetic diversity of the bacterial wilt pathogen in the country.

The main objectives of the present study were to (i) determine whether or not the bacterial wilt pathogen could be present across major potato-growing areas of Iran, (ii) assess the host range of $R$. solanacearum strains isolated from potato plants on a set of taxonomically diverse annual crops, and (iii) determine the phylogenetic position and taxonomic status of the strains using a five-gene MLSA/MLST scheme (egl, fliC, gyrB, mutS, and $r p l B)$. Host range assays, specific PCRs, and MLSA/MLST revealed that the strains associated with bacterial wilt of potato in Iran belong to the phylotype IIB/sequevar I of the RSSC.

\section{MATERIALS AND METHODS}

Surveys, sampling, and bacterial isolation. During 2017 to 2018, field surveys and inspections were conducted across potato-growing areas in Central (Chaharmahal-Bakhtiari), Western (Hamadan and Kurdistan), Southwestern (Khuzestan) and Southern (Fars and Kerman) provinces in Iran to monitor the status of bacterial wilt disease in the areas. Eggplant-, pepper-, and tomatogrowing fields in the neighborhood of potato fields were also surveyed for bacterial wilt symptoms. Potato plants showing wilting and vascular brown rot symptoms were sampled and brought to the laboratory for further analyses. Potato tubers and stems were surface-sterilized by dipping into $0.5 \%$ sodium hypochlorite for $2 \mathrm{~min}$ and rinsed three times in sterile distilled water (SDW). Small portions of vascular tissues were aseptically cut and macerated in a few drops of SDW using a sterile mortar and a pestle. A loopful of the resulting suspensions was streaked onto casamino acid-peptone-glucose (CPG) agar medium amended by 2,3,5-triphenyl tetrazolium chloride (TTC) as recommended previously (Kelman 1954). The plates were incubated at 25 to $27^{\circ} \mathrm{C}$ for 3 to 4 days, and the resulting colonies were purified with multiple streaking onto fresh TTC medium. The bacterial strains (Table 1) were maintained in $15 \%$ glycerol at $-70^{\circ} \mathrm{C}$ for further use and long-term storage. Furthermore, five $R$. solanacearum strains that were previously isolated from potato plants in Isfahan and Khuzestan provinces were obtained from Isfahan University of Technology (Isfahan, Iran) and included in the forthcoming pathogenicity and molecularphylogenetic analyses.

Pathogenicity and host range assays. All the bacterial strains (Table 1) were evaluated for their pathogenicity on their host of isolation (potato) in greenhouse conditions. Furthermore, to determine their potential host range and race status, they were inoculated on a set of taxonomically diverse annual crops and weed species that were previously reported as experimental hosts of different races of the pathogen (Elphinstone 2005). Annual crops and weed species within different botanical families such as Asteraceae, i.e., sunflower (Helianthus annuus 'Jaguar') and zinnia (Zinnia elegans); Cucurbitaceae, i.e., cucumber (Cucumis sativus 'Biet Alpha') and zucchini (Cucurbita pepo var. cylindrical 'KC362002'); Fabaceae, i.e., common bean (Phaseolus vulgaris 'Sadri') and cowpea (Vigna unguiculata 'Partow'), and Solanaceae, i.e., bell pepper (Capsicum annuum 'California Wonder'), eggplant (Solanum melongena 'Emami'), potato ('Spirit'), red nightshade (Solanum villosum), and tomato (Solanum lycopersicum 'Superchief') were grown in greenhouse conditions as described previously (Osdaghi et al. 2018c). In brief, all the plant species were grown in 20-cm diameter pots (five plants/pot) and were maintained in greenhouse at ambient conditions $\left(24\right.$ to $27^{\circ} \mathrm{C}, 14 \mathrm{~h}$ natural light). The plants were inoculated at 10 to 15 days postemergence, when they had at least five to six fully expanded leaves (approximately 15 to $20 \mathrm{~cm}$ height; red nightshade at eight-leaf stage). Inoculation was made by inserting a sterile dissecting needle dipped into a freshly prepared bacterial suspension gown on TTC medium $\left(1 \times 10^{8} \mathrm{CFU}\right.$ $\mathrm{ml}^{-1}$ in SDW) through the first internode of each plant (EPPO 2018). The inoculated plants were kept in greenhouse at ambient temperature ( 24 to $27^{\circ} \mathrm{C}, 14 \mathrm{~h}$ natural light, and 70 to $80 \%$ relative humidity) and they were periodically monitored (in 5-day intervals) for the appearance of disease symptoms up to 30 days postinoculation (dpi). Reference strain of $R$. solanacearum (UW365; phylotype IIB/sequevar I) and SDW were used as positive and negative controls, respectively. Koch's postulates were performed by re-isolating the inoculated strains on TTC medium from the stems of all inoculated plants. The identity of re-isolated bacterial strains were confirmed by colony characteristics on TTC medium, Gram staining, and PCR assays using the species-specific primer pair 759/760 (Opina et al. 1997). All the experiments were conducted twice.

Disease severity (DS) was assessed indirectly using a wilting index on an ordinal rating scale with five (0 to 4$)$ symptom scales: where $0=$ no symptoms, $1=$ one wilted leaf, $2=$ two or three wilted leaves, $3=$ all leaves wilted, and $4=$ stem collapsed and plant death. Disease severity was recorded in 5-day intervals, i.e., 5, 10, 15, 20, 25, and 30 dpi (Coupat-Goutaland et al. 2011). Disease severity measurements were converted from original ordinal scale to a ratio scale and normalized to 0 to 1 using the following equation: 


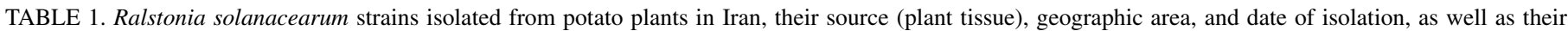

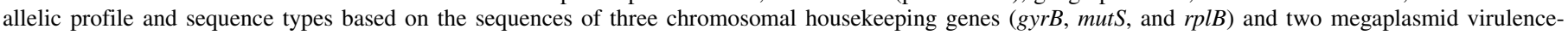
associated genes $(e g l \text { and } f l i C)^{\mathrm{a}}$

\begin{tabular}{|c|c|c|c|c|c|c|c|c|c|c|c|c|}
\hline \multirow[b]{2}{*}{ Strain } & \multirow[b]{2}{*}{ Year } & \multirow[b]{2}{*}{ Source } & \multirow{2}{*}{$\begin{array}{l}\text { Iran province } \\
\text { or country }\end{array}$} & \multirow[b]{2}{*}{ County } & \multirow[b]{2}{*}{ Phylotype } & \multirow{2}{*}{$\begin{array}{c}\text { egl-based } \\
\text { sequevar }\end{array}$} & \multicolumn{5}{|c|}{ Allelic profile } & \\
\hline & & & & & & & egl & fliC & gyrB & mutS & $r p l B$ & Sequence type \\
\hline Strains fron & & & & & & & & & & & & \\
\hline $\mathrm{K} 1$ & 2017 & Tuber & Kurdistan & Dehgolan & IIB & 1 & 1 & 1 & 2 & 2 & 1 & 2 \\
\hline $\mathrm{K} 2$ & 2017 & Tuber & Kurdistan & Dehgolan & IIB & 1 & 1 & 1 & 2 & 2 & 1 & 2 \\
\hline $\mathrm{K} 3$ & 2017 & Tuber & Kurdistan & Dehgolan & IIB & 1 & 1 & 1 & 2 & 2 & 1 & 2 \\
\hline K4 & 2017 & Tuber & Kurdistan & Dehgolan & IIB & 1 & 1 & 1 & 2 & 2 & 1 & 2 \\
\hline K5 & 2017 & Tuber & Kurdistan & Dehgolan & IIB & 1 & 1 & 1 & 2 & 2 & 1 & 2 \\
\hline K6 & 2017 & Tuber & Kurdistan & Dehgolan & IIB & 1 & 1 & 1 & 1 & 2 & 1 & 1 \\
\hline K7 & 2017 & Tuber & Kurdistan & Dehgolan & IIB & 1 & 1 & 1 & 1 & 2 & 1 & 1 \\
\hline K8 & 2017 & Tuber & Kurdistan & Dehgolan & IIB & 1 & 1 & 1 & 1 & 2 & 1 & 1 \\
\hline K9 & 2017 & Stem & Kurdistan & Dehgolan & IIB & 1 & 1 & 1 & 2 & 2 & 1 & 2 \\
\hline K10 & 2017 & Tuber & Kurdistan & Dehgolan & IIB & 1 & 1 & 1 & 2 & 3 & 1 & 4 \\
\hline K11 & 2017 & Tuber & Kurdistan & Dehgolan & IIB & 1 & 1 & 1 & 1 & 2 & 1 & 1 \\
\hline K12 & 2017 & Tuber & Kurdistan & Dehgolan & IIB & 1 & 1 & 1 & 1 & 2 & 1 & 1 \\
\hline K13 & 2017 & Tuber & Kurdistan & Dehgolan & IIB & 1 & 1 & 1 & 2 & 2 & 1 & 2 \\
\hline K14 & 2017 & Tuber & Kurdistan & Dehgolan & IIB & 1 & 1 & 1 & 1 & 2 & 1 & 1 \\
\hline K15 & 2017 & Stem & Kurdistan & Dehgolan & IIB & 1 & 1 & 1 & 1 & 2 & 1 & 1 \\
\hline K16 & 2017 & Tuber & Kurdistan & Dehgolan & IIB & 1 & 1 & 1 & 1 & 2 & 1 & 1 \\
\hline H17 & 2017 & Tuber & Hamadan & Bahar & IIB & 1 & 1 & 1 & 2 & 2 & 1 & 2 \\
\hline H18 & 2017 & Tuber & Hamadan & Bahar & IIB & 1 & 1 & 1 & 1 & 2 & 1 & 1 \\
\hline H19 & 2017 & Tuber & Hamadan & Bahar & IIB & 1 & 1 & 1 & 1 & 2 & 1 & 1 \\
\hline $\mathrm{H} 20$ & 2017 & Tuber & Hamadan & Bahar & IIB & 1 & 1 & 1 & 1 & 2 & 1 & 1 \\
\hline $\mathrm{H} 21$ & 2017 & Tuber & Hamadan & Bahar & IIB & 1 & 1 & 1 & 2 & 2 & 1 & 2 \\
\hline K22 & 2017 & Tuber & Kurdistan & Dehgolan & IIB & 1 & 1 & 1 & 2 & 2 & 1 & 2 \\
\hline K23 & 2017 & Tuber & Kurdistan & Dehgolan & IIB & 1 & 1 & 1 & 1 & 2 & 1 & 1 \\
\hline K24 & 2017 & Tuber & Kurdistan & Dehgolan & IIB & 1 & 1 & 1 & 1 & 2 & 1 & 1 \\
\hline $\mathrm{K} 25$ & 2017 & Tuber & Kurdistan & Dehgolan & IIB & 1 & 1 & 1 & 2 & 2 & 1 & 2 \\
\hline $\mathrm{H} 26$ & 2017 & Tuber & Hamadan & Bahar & IIB & 1 & 1 & 1 & 2 & 2 & 1 & 2 \\
\hline $\mathrm{H} 27$ & 2017 & Tuber & Hamadan & Bahar & IIB & 1 & 1 & 1 & 1 & 2 & 1 & 1 \\
\hline $\mathrm{H} 28$ & 2017 & Tuber & Hamadan & Bahar & IIB & 1 & 1 & 1 & 2 & 2 & 1 & 2 \\
\hline $\mathrm{H} 29$ & 2017 & Tuber & Hamadan & Bahar & IIB & 1 & 1 & 1 & 2 & 2 & 1 & 2 \\
\hline H30 & 2017 & Tuber & Hamadan & Bahar & IIB & 1 & 1 & 1 & 2 & 2 & 1 & 2 \\
\hline H31 & 2017 & Tuber & Hamadan & Bahar & IIB & 1 & 1 & 1 & 2 & 2 & 1 & 2 \\
\hline K32 & 2017 & Tuber & Kurdistan & Dehgolan & IIB & 1 & 1 & 1 & 2 & 2 & 1 & 2 \\
\hline Kh33 & 2018 & Tuber & Khuzestan & Shushtar & IIB & 1 & 1 & 1 & 2 & 2 & 1 & 2 \\
\hline Kh34 & 2018 & Stem & Khuzestan & Shushtar & IIB & 1 & 1 & 1 & 2 & 2 & 2 & 3 \\
\hline Kh35 & 2018 & Tuber & Khuzestan & Shushtar & IIB & 1 & 1 & 1 & 2 & 2 & 1 & 2 \\
\hline Kh36 & 2018 & Stem & Khuzestan & Shushtar & IIB & 1 & 1 & 1 & 2 & 2 & 1 & 2 \\
\hline Kh37 & 2018 & Tuber & Khuzestan & Shushtar & IIB & 1 & 1 & 1 & 2 & 2 & 2 & 3 \\
\hline $\mathrm{Kh} 38$ & 2018 & Tuber & Khuzestan & Shushtar & IIB & 1 & 1 & 1 & 2 & 2 & 2 & 3 \\
\hline Kh39 & 2018 & Tuber & Khuzestan & Shushtar & IIB & 1 & 1 & 1 & 2 & 2 & 2 & 3 \\
\hline $\mathrm{Kh} 40$ & 2018 & Stem & Khuzestan & Shushtar & IIB & 1 & 1 & 1 & 1 & 2 & 1 & 1 \\
\hline Kh41 & 2018 & Tuber & Khuzestan & Shushtar & IIB & 1 & 1 & 1 & 2 & 2 & 2 & 3 \\
\hline $\mathrm{Ke} 42$ & 2018 & Tuber & Kerman & Mahan & IIB & 1 & 1 & 1 & 1 & 2 & 1 & 1 \\
\hline $\mathrm{Ke} 43$ & 2018 & Tuber & Kerman & Dashtkar & IIB & 1 & 1 & 1 & 1 & 2 & 1 & 1 \\
\hline $\mathrm{Ke} 44$ & 2018 & Tuber & Kerman & Dashtkar & IIB & 1 & 1 & 1 & 1 & 2 & 1 & 1 \\
\hline $\mathrm{Ke} 45$ & 2018 & Tuber & Kerman & Dashtkar & IIB & 1 & 1 & 1 & 1 & 2 & 1 & 1 \\
\hline $\mathrm{Ke} 46$ & 2018 & Stem & Kerman & Dashtkar & IIB & 1 & 1 & 1 & 1 & 2 & 1 & 1 \\
\hline $\mathrm{Ke} 47$ & 2018 & Tuber & Kerman & Dashtkar & IIB & 1 & 1 & 1 & 1 & 2 & 1 & 1 \\
\hline $\mathrm{Ke} 48$ & 2018 & Tuber & Kerman & Dashtkar & IIB & 1 & 1 & 1 & 1 & 2 & 1 & 1 \\
\hline $\mathrm{Ke} 49$ & 2018 & Tuber & Kerman & Dashtkar & IIB & 1 & 1 & 1 & 1 & 2 & 1 & 1 \\
\hline Ke50 & 2018 & Tuber & Kerman & Dashtkar & IIB & 1 & 1 & 1 & 1 & 2 & 1 & 1 \\
\hline Ch51 & 2018 & Tuber & $\begin{array}{c}\text { Chaharmahal- } \\
\text { Bakhtiari }\end{array}$ & Sefiddasht & IIB & 1 & 1 & 1 & 1 & 2 & 1 & 1 \\
\hline Ch52 & 2018 & Tuber & $\begin{array}{c}\text { Chaharmahal- } \\
\text { Bakhtiari }\end{array}$ & Sefiddasht & IIB & 1 & 1 & 1 & 2 & 2 & 1 & 2 \\
\hline F53 & 2018 & Tuber & Fars & Eqlid & IIB & 1 & 1 & 1 & 2 & 2 & 1 & 2 \\
\hline F54 & 2018 & Tuber & Fars & Eqlid & IIB & 1 & 1 & 1 & 2 & 2 & 1 & 2 \\
\hline PS54 & 2002 & Potato & Isfahan & Isfahan & IIB & 1 & 1 & 1 & 1 & 2 & 1 & 1 \\
\hline Q31 & 2013 & Potato & Isfahan & Daran & IIB & 1 & 1 & 1 & 2 & 2 & 1 & 2 \\
\hline RS11 & 2015 & Potato & Isfahan & Damaneh & IIB & 1 & 1 & 1 & 2 & 2 & 1 & 2 \\
\hline RS95 & 2016 & Potato & Isfahan & Faridan & IIB & 1 & 1 & 1 & 1 & 2 & 1 & 1 \\
\hline Sh16 & 2003 & Tuber & Khuzestan & Shushtar & IIB & 25 & 2 & 1 & 3 & 1 & 1 & 6 \\
\hline Reference $\mathrm{s}$ & rom dif & rent countries & & & & & & & & & & \\
\hline UW365 & 1980 & Potato & China & ND & IIB & 1 & 1 & 1 & 2 & 2 & 1 & 2 \\
\hline IPO1609 & 1995 & Potato & Netherlands & ND & IIB & 1 & 1 & 1 & 2 & 2 & 1 & 2 \\
\hline UW551 & 2003 & Pelargonium & Kenya & ND & IIB & 1 & 1 & 1 & 2 & 2 & 1 & 2 \\
\hline CFBP3858 & 1995 & Potato & Netherlands & ND & IIB & 1 & 1 & 1 & 3 & 1 & 1 & 5 \\
\hline UY031 & 2003 & Potato & Uruguay & ND & IIB & 1 & 1 & 1 & 2 & 2 & 1 & 2 \\
\hline GEO_55 & 2013 & Potato & Georgia & ND & IIB & 1 & 1 & 1 & 2 & 2 & 1 & 2 \\
\hline
\end{tabular}

a ND, not determined. Sequence type is based on TCS sequence type network as shown in Figure 3. 


$$
\begin{aligned}
\mathrm{DS}= & {[(0 \times \mathrm{a})+(1 \times \mathrm{b})+(2 \times \mathrm{c})+(3 \times \mathrm{d})} \\
& +(4 \times \mathrm{e})] /[(\mathrm{a}+\mathrm{b}+\mathrm{c}+\mathrm{d}+\mathrm{e}) \times 4]
\end{aligned}
$$

where a, b, c, d, and e are the corresponding numbers of infected plants scored from 0 to 4 . Mean and standard deviation of disease severity index was calculated for every pathosystem consisting of $R$. solanacearum strains isolated in Iran and each of the symptomatic plant species and presented as a stacked bar graph. Separate stacked bar graphs were prepared for the 5, 10, 15, 20, 25, and $30 \mathrm{dpi}$ measurements on four solanaceous crops (eggplant, pepper, potato, and tomato).

Molecular-phylogenetic analyses. Specific PCR assays. All the strains with a typical $R$. solanacearum morphology on TTC medium (i.e., creamy white colonies with a pink center) were subjected to PCR tests using the RSSC-specific primer pair 759/760 (Opina et al. 1997). Furthermore, a multiplex PCR using a set of five phylotype-specific primers (Nmult21:1F, Nmult21:2F, Nmult22:InF, Nmult23:AF, and Nmult22:RR) was performed to assign the bacterial strains into their corresponding phylotype (Fegan and Prior 2005; Mahbou Somo Toukam et al. 2009). Primer sequences and size of the expected amplicon in each primer pair are described in Table 2. Strains that were classified in phylotype II were further investigated using the primer pair 630-F/631-R (Fegan et al. 1998), to test their affiliation to "potato brown rot ecotype" which is equivalent to phylotype IIB/ sequevar 1 (IIB-1). Bacterial DNA was extracted using the Expin Combo GP (GeneAll, Tic Tech Centre, Singapore) DNA extraction kit, following the protocol of the manufacturer. The quality and quantity of the DNAs were spectrophotometrically evaluated and adjusted to $50 \mathrm{ng} \mu \mathrm{l}^{-1}$ using the NanoDrop ND-100 (Nanodrop Technologies, Waltham, MA). For PCR reactions, Universal PCR Kit, Ampliqon Taq DNA Polymerase Master Mix Red (Ampliqon A/S, Odense, Denmark) was applied according to the manufacturer's recommendations. For each strain, a 50- $\mu$ l PCR including 50 ng of total DNA and $2 \mu \mathrm{l}$ of each primer $\left(10 \mathrm{pmol}^{\mathrm{l}} \mathrm{l}^{-1}\right)$ were used. Annealing temperature for each of the primer pairs is described in Table 2 .

Phylogenetic analyses. To determine the egl-based sequevar status of the strains isolated in Iran, a 750-bp DNA fragment of $e g l$ gene was amplified and sequenced using the primer pair EndoF/ EndoR (Table 2) (Fegan and Prior 2005; Mahbou Somo Toukam et al. 2009). Furthermore, to obtain precise and reliable data on the phylogenetic position of the strains isolated in Iran, we performed a five-gene MLSA based on three housekeeping genes ( $g y r B$, mutS, and $r p l B$ ) and two virulence-associated genes $(e g l$ and $f l i C)$, located on the chromosome and megaplasmid of $R$. solanacearum, respectively (Castillo and Greenberg 2007; Wicker et al. 2012). These selected loci can reliably resolve the evolutionary relationships among the RSSC lineages (Castillo and Greenberg 2007; Wicker et al. 2012). The sequences and annealing temperature of primer pairs are shown in Table 2, while the PCR procedure was the same as described above. The amplified PCR products were sent to Bioneer Corporation (http://www.bioneer.com) to be sequenced using both the forward and reverse primers via Sanger technology. Resulted consensus sequences of all the five genes were subjected to BLASTn analysis on the Nucleotide Collection (nr/nt) database of the NCBI GenBank to determine their similarity to the reference strains of the RSSC. Furthermore, corresponding sequences of these

\begin{tabular}{|c|c|c|c|c|c|c|c|c|c|c|c|c|}
\hline \multirow[b]{2}{*}{ Strain } & \multirow[b]{2}{*}{ Year } & \multirow[b]{2}{*}{ Source } & \multirow{2}{*}{$\begin{array}{l}\text { Iran province } \\
\text { or country }\end{array}$} & \multirow[b]{2}{*}{ County } & \multirow[b]{2}{*}{ Phylotype } & \multirow{2}{*}{$\begin{array}{c}\text { egl-based } \\
\text { sequevar }\end{array}$} & \multicolumn{5}{|c|}{ Allelic profile } & \multirow[b]{2}{*}{ Sequence type } \\
\hline & & & & & & & egl & fliC & gyrB & mutS & $r p l B$ & \\
\hline GEO_304 & 2013 & Potato & Georgia & ND & IIB & 1 & 1 & 1 & 2 & 2 & 1 & 2 \\
\hline GEO_81 & 2014 & Potato & Georgia & ND & IIB & 1 & 1 & 1 & 2 & 2 & 1 & 2 \\
\hline GEO_6 & 2011 & Potato & Georgia & ND & IIB & 1 & 1 & 1 & 2 & 2 & 1 & 2 \\
\hline GEO_99 & 2015 & Pepper & Georgia & ND & IIB & 1 & 1 & 1 & 2 & 2 & 1 & 2 \\
\hline GEO_57 & 2014 & Potato & Georgia & ND & IIB & 1 & 1 & 1 & 2 & 2 & 1 & 2 \\
\hline UW $2 \overline{4}$ & 1951 & Potato & Israel & ND & IIB & 1 & 1 & 1 & 2 & 2 & 1 & 2 \\
\hline POPS2 & 1980 & ND & China & ND & IIB & 1 & 1 & 1 & 2 & 2 & 1 & 2 \\
\hline CFIA906 & 1962 & Potato & India & ND & IIB & 1 & 1 & 1 & 2 & 2 & 1 & 2 \\
\hline NCPPB_909 & 1961 & Potato & Egypt & ND & IIB & 1 & 1 & 1 & 2 & 2 & 1 & 2 \\
\hline GEO_96 & 2015 & Tomato & Georgia & ND & IIB & 1 & 1 & 1 & 2 & 2 & 1 & 2 \\
\hline
\end{tabular}

TABLE 1. (Continued from previous page)

\begin{tabular}{|c|c|c|c|c|c|}
\hline Primer name & $5^{\prime}-3^{\prime}$ sequence & $\begin{array}{l}\text { Size of amplicon } \\
\text { (bp) }\end{array}$ & $\begin{array}{c}\text { Annealing } \\
\text { temperature }\left({ }^{\circ} \mathrm{C}\right)\end{array}$ & Target & Reference \\
\hline 759 & GTCGCCGTCAACTCACTTTCC & 280 & 63 & $16 \mathrm{~S}-23 \mathrm{~S}$ intergenic & Opina et al. 1997 \\
\hline 760 & GTCGCCGTCAGCAATGCGGAATCG & & & spacer & \\
\hline $630-\mathrm{F}$ & ATACAGAATTCGACCGGCACG & 278 & 60 & 16s rDNA & Fegan et al. 1998 \\
\hline 631-R & AATCACATGCAATTCGCCTACG & & & & \\
\hline Nmult21:1:F & CGTTGATGAGGCGCGCAATTT & 144: phylotype I & 59 & ITS & Fegan and Prior 2005 \\
\hline Nmult21:2:F & AAGTTATGGACGGTGGAAGTC & 372: phylotype II & & & \\
\hline Nmult22:InF & ATTGCCAAGACGAGAGAAGTA & 91: phylotype III & & & \\
\hline Nmult23:AF & ATTACGAGAGCAATCGAAAGATT & 213: phylotype IV & & & \\
\hline Nmult22:RR & TCGCTTGACCCTATAACGAGTA & & & & \\
\hline mutS.RsF.1570 & ACAGCGCCTTGAGCCGGTACA & 758 & 66 & mutS & Fegan and Prior 2005 \\
\hline mutS.RsR.1926 & GCTGATCACCGGCCCGAACAT & & & & \\
\hline$r p l B-\mathrm{RS} 01 \mathrm{~F}$ & ATGGCACTCGTCAAGACCAA & 814 & 61 & $r p l B$ & Wicker et al. 2012 \\
\hline$r p l B-\mathrm{RS} 814 \mathrm{R}$ & TTAACGCTTGTGACGGCG & & & & \\
\hline GyrBF & AGGGCTTCGTCGAGTACATCAA & 1,200 & 66 & gyrB & Castillo and Greenberg \\
\hline GyrBR & GTTCCGCCGAGGCTCCACG & & & & 2007 \\
\hline Endo-F & ATGCATGCCGCTGGTCGCCGC & 750 & 70 & $e g l$ & Fegan and Prior 2005 \\
\hline Endo-R & GCGTTGCCCGGCACGAACACC & & & & \\
\hline Rsol-fliC-F & GAACGCCAACGGTGCGAACT & 400 & 63 & fliC & Schonfeld et al. 2003 \\
\hline Rsol-fliC-R & GGCGGCCTTCAGGGAGGTC & & & & \\
\hline
\end{tabular}

TABLE 2. Primer pairs used in this study 
five genes in a set of worldwide RSSC strains were retrieved from the GenBank database and included in the phylogenetic analyses (Benson et al. 2017; Clarke et al. 2015). The sequences were concatenated following the alphabetic order of the genes using MEGA7 software (Kumar et al. 2016) and aligned using MAFFT online service (Katoh et al. 2019), producing a sequence of 2,938 bp: nucleotides 1 to 665 for $\mathrm{egl}, 666$ to 980 for fliC (315 bp), 981 to 1,675 for $g y r B$ (695 bp), 1,676 to 2,289 for $m u t S$ (614 bp), and 2,290 to 2,938 for $r p l B$ (649 bp) genes. Phylogenetic tree was constructed using the concatenated sequences of five genes via maximum likelihood method with MEGA7. The model of evolution for maximum likelihood analysis was determined using Modeltest tab in MEGA7, and the phylogenetic tree was constructed with bootstrapping (1,000 replications). Maximum likelihood method was used to generate phylogenetic trees from the sequences of individual genes using the same procedure as described for the concatenated sequences.

MLST and genetic diversity. Nucleotide diversity, number of alleles (haplotypes) and sequence types (STs), allelic diversity, allele frequency, percentage of polymorphic sites, and the minimum number of recombination events were estimated using DnaSP 5.10 software for the individual gene sequences as well as the concatenated dataset of IIB/I strains (Librado and Rozas 2009). An ST is a group of alleles that are inherited together from a single parental bacterial strain. The class I neutrality tests (i.e., Tajima's D, Fu and Li's D*, and Fu and Li's F* statistics) were also calculated for detecting departure from the mutation/drift equilibrium (Librado and Rozas 2009). Multiple methods were used to detect recombination events among the loci/strains. Detection of potential recombinant sequences and identification of likely parental sequences were carried out using a set of seven non-parametric detection methods (RDP, Geneconv, MaxChi, Chimaera, BootScan, SiScan, and 3Seq) implemented in Recombination Detection Program (RDP) version 4.80 (Martin et al. 2015). The analysis was performed with default settings for different detection methods, and the Bonferroni-corrected $P$ value cutoff was set at 0.05 . Recombination events were accepted when they were identified by at least four out of seven detection methods (Martin et al. 2015).

NeighborNet networks were constructed and the pairwise homoplasy index (PHI-Test) was calculated for the individual gene sequences as well as the concatenated dataset using SplitsTree version 4.14.4 (Huson and Bryant 2006). SplitsTree provides a network-based phylogeny visualizing recombination among different strains, while the relationships between recombining strains cannot be sufficiently represented by a tree-based maximum likelihood phylogeny which implies strictly bifurcating relationships. Furthermore, to visualize the STs among the strains, haplotype network was generated for the concatenated sequences using the TCS algorithm (Clement et al. 2002) implemented in PopART v. 1.7 program (Leigh and Bryant 2015). The geographic origin of $58 \mathrm{IIB} / \mathrm{I}$ strains collected in seven Iranian provinces as well as the 16 GenBank sequences (Table 1) was assigned into the haplotype network as described by Leigh and Bryant (2015). The province-specific STs and shared STs between the provinces were identified and quantified based on the resulted network.

GenBank accession numbers and strains availability. The sequenced nucleotides were deposited into GenBank database under the following accession numbers: MN201623 to MN201681 for egl; MN201682 to MN201740 for fliC; MN201741 to MN201799 for gyrB; MN201800 to MN201858 for mutS; and MN201859 to MN201917 for $r p l B$. Furthermore, a pure culture of representative strains isolated in Iran was deposited in CIRM-CFBP culture collection (French Collection for Plant-Associated Bacteria) and assigned accession numbers as follow: K2 = CFBP 8695, Ke44 = CFBP 8696, and Sh16 = CFBP 8697 (Sedighian et al. 2020).

\section{RESULTS}

Disease distribution and bacterial strains. Potato-growing areas in six provinces in Iran, i.e., Chaharmahal-Bakhtiari, Fars,
Hamadan, Kerman, Khuzestan, and Kurdistan, were surveyed for the occurrence and distribution of bacterial wilt disease. The size of the surveyed fields varied from 0.1 to 5 ha. Potato plants showing bacterial wilt symptoms were observed in all the surveyed provinces, although prevalence of the disease was higher in Kurdistan and Hamadan provinces (Fig. 1). Symptomatic potato plants showed brown discoloration and necrosis of vascular tissues on the above-ground sections. Furthermore, bacterial ooze exudation was frequently observed on the eyes and stolon attachment of potato tubers in the fields where the aerial symptoms were detected (Supplementary Fig. S1). However, no bacterial wilt symptoms were observed on eggplant, pepper, and tomato plants surveyed in the geographic areas described above.

A total of 54 bacterial strains (Table 1) were isolated from the symptomatic potato tissues (tubers and stems) during 2017 to 2018. All the bacterial strains were morphologically similar to RSSC strains. The strains isolated in this study (except for Ch51, Ch52, and K14) showed large irregular, creamy white, and fluidal colonies with a typical pink pigmentation in the colony center on CPG agar medium amended by 2,3,5-triphenyl tetrazolium chloride (TTC) $96 \mathrm{~h}$ postincubation. However, the strain Ch51 showed smaller colonies in diameter, and the strains Ch52 and K14 showed round red colonies with narrow white halo on the same medium. According to the morphological characteristics of the bacterial strains, they were initially identified as the members of RSSC, while their identity was further confirmed using the 759/760 PCR primers, which directed the amplification of a 280-bp DNA fragment in all the strains isolated in this study.

Among the RSSC strains evaluated in this study, 21 and 11 strains were isolated in Kurdistan and Hamadan provinces, respectively. In Kerman and Fars provinces, eight and two strains were isolated in Dashtkar and Eqlid counties, respectively. Additionally, nine and two strains were isolated in Shushtar and Sefiddasht counties in Khuzestan and Chaharmahal-Bakhtiari provinces, respectively (Table 1). Beside the strains isolated in this study, we also received five strains (PS54, Q31, RS11, RS95, and Sh16) from Isfahan University of Technology, isolated from the initial potato outbreaks in Isfahan and Khuzestan provinces from 2002 to 2016. Our

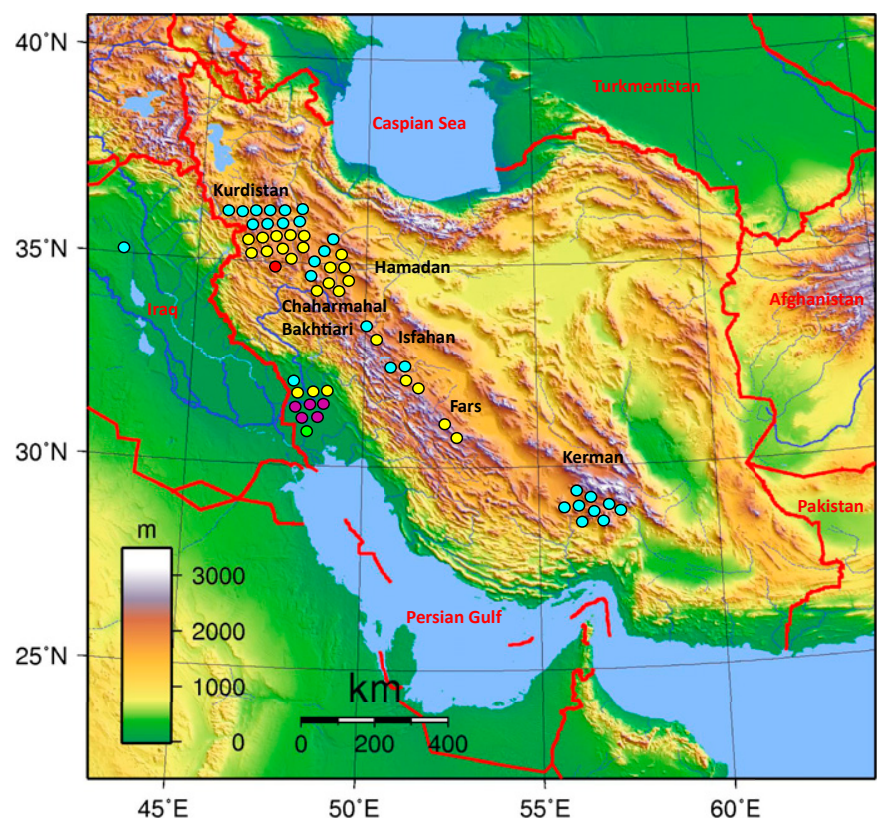

Fig. 1. Distribution map of potato bacterial wilt disease caused by Ralstonia solanacearum in Iran. Each circle represents one $R$. solanacearum strain isolated in different fields in the surveyed areas. Each color represents one of the sequence types shown in Figure 3. Blue, sequence type (ST)1; yellow, ST2; violet, ST3; red, ST4; and green, ST6. The original map was obtained from https://commons.wikimedia.org/wiki/File:Iran_Topography.png. 
collection thus consisted of a total of 59 strains from Iran. Most of the surveyed areas in this study could be regarded as "highlands" (altitudes above 1,000 $\mathrm{m}$ above sea level [masl]), while Khuzestan province was considered "lowlands" since the potato-growing fields were situated below 100 masl (Fig. 1).

Pathogenicity and host range assays. All the RSSC strains evaluated in this study, except Ch52, K14, and Sh16, were pathogenic on solanaceous crops (eggplant, pepper, potato, and tomato), as well as red nightshade (S. villosum) in greenhouse conditions. The most severe symptoms were observed on tomato plants, which showed wilting on leaves at only 4 to $5 \mathrm{dpi}$, while eggplant, pepper, and potato plants showed symptom development starting at 6 to $10 \mathrm{dpi}$ (Supplementary Fig. S1). All the inoculated tomato plants-except for those inoculated with Ch52, K14, and Sh16 strains-showed $100 \%$ wilting symptoms and plant death at 10 to 12 dpi. On eggplant and pepper plants, initial symptoms were observed at 6 to $8 \mathrm{dpi}$ and the plants died at 15 to $20 \mathrm{dpi}$. On potato plants, initial symptoms were observed at 9 to $11 \mathrm{dpi}$, while entire wilting and plant death occurred at 20 to 22 dpi (Supplementary Fig. S2). However, the strains Ch52, K14, and Sh16 showed attenuated aggressiveness, and were only pathogenic on tomato and potato on which wilting symptoms started from 15 to 20 dpi with no mortality on the plants. On the other hand, none of the non-solanaceous plant species evaluated in this study (common bean, cowpea, cucumber, sunflower, zinnia, and zucchini) showed wilting symptoms under greenhouse conditions, indicating that the host range of the potato strains isolated in Iran was limited to solanaceous plant species. Bacterial strains, as those originally inoculated, were consistently re-isolated from symptomatic plants on TTC medium and their identity was confirmed by their colony morphology on culture medium, Gram staining, as well as the species-specific primer pair $759 / 760$ as described above. Negative control plants inoculated with SDW remained healthy, while the positive control solanaceous plants inoculated with the reference strain UW365 showed wilting symptoms at 5 to 12 dpi depending on the plant species. Similar results were consistently observed in both replications of pathogenicity and host range tests.

Molecular-phylogenetic analyses. Specific PCR assays. PCR diagnosis tests using the species-specific primer pair 759/ 760 confirmed that all the strains evaluated in this study were members of the RSSC. Furthermore, Fegan and Prior's multiplex PCR assigned all the strains to the phylotype II of RSSC. On the other hand, the Race 3/biovar 2-specific PCR primer pair 630-F/ 631-R directed the amplification of the expected 278-bp DNA fragment in all the strains except for Sh16. From these results, all the strains isolated in this study belong to the RSSC phylotype II, and all except Sh16 belong to the phylotype IIB/sequevar 1 (synonymous to race 3/biovar 2, R3B2), corresponding to $R$. solanacearum in Safni's new nomenclature (Safni et al. 2014). As for topological characteristics of the areas where the bacterial strains were isolated (as depicted in Fig. 1), all the strains evaluated in this study, except for those of Khuzestan strains, were isolated from the areas with $>1,000$ masl altitude, which was in congruence with the fact that the IIB/1 strains of RSSC are more likely to be adapted to cool temperature areas. Interestingly, in the Khuzestan plain (Southwestern Iran) where warm and humid conditions prevail, potato cultivation is restricted to the span of November to April timeframe when the average temperature is low.

Phylogenetic analyses and genetic diversity. BLASTn search using the $e g l$ gene sequences on the NCBI GenBank database revealed that the strains isolated in Iran, except for Sh16, had the highest sequence identity $(100 \%)$ with the standard strains of phylotype IIB/sequevar 1. The strain Sh16 showed the highest sequence similarity to the phylotype IIB/sequevar 25 (synonymous to biovar 2T). The egl-based maximum likelihood phylogeny-supported with high bootstrap values-confirmed that all the strains isolated in Iran (except for Sh16) belong to phylotype IIB/sequevar 1 of RSSC, while Sh16 belongs to sequevar 25
(Supplementary Fig. S3). Subsequently, MLSA using the concatenated sequences of five housekeeping and virulence-associated genes $(e g l, f l i C, g y r B, m u t S$, and $r p l B)$ was performed on all the 59 strains isolated in Iran, as well as the corresponding sequences in 16 strains retrieved from the NCBI GenBank database. Phylogenetic tree constructed using the dataset of concatenated sequences using Tamura-Nei + Gamma Distributed model (TN93+G) confirmed the results obtained from the $e g l$ phylogeny (Fig. 2). All the strains isolated in Iran except for Sh16 were clustered in a monophyletic clade along with the reference strains of phylotype IIB/sequevar 1, although they were presenting different STs. Similar results were obtained when the sequences of individual genes were subjected to the phylogenetic analysis (data not shown).

Sequence variation statistics and diversity parameters were calculated using DnaSP 5.10 software for each of the five genes, as well as the concatenated sequences in all IIB/I strains evaluated in this study (Table 3). The strains isolated in Iran carried different allelic forms and corresponded to five STs based on the concatenated sequences of the five genes (Table 3; Fig. 3). Among the Iranian strains of the pathogen, one, one, three, three, and two alleles were detected in the egl, fliC, gyrB, mutS, and $r p l B$ sequences, respectively (Table 1 ). Reticulations were observed in the NeighborNet-based phylogenetic network generated using the concatenated sequences of the five genes, suggesting possible recombination events within the population in Iran (data not shown). However, the PHI-Test results obtained using SplitsTree did not find statistically significant evidence for recombination in the concatenated dataset, nor in the sequences of individual five genes. Results of the PHI-Test were in congruence with those of the recombination detection program (RDP) and DnaSP results, which did not find statistically significant evidence for recombination. Population neutrality indices (i.e., Fu and Li's D*and Fu and Li's $\mathrm{F}^{*}$ ) were significantly negative only in the concatenated dataset of sequences as well as the $m u t S$ gene (Table 3), suggesting a recent selective sweep and/or population expansion after a recent bottleneck. However, considering the nonsignificant results obtained in $\mathrm{egl}$, fliC, $g y r B$, and $r p l B$ gene sequences, further investigations using the sequences of additional housekeeping genes are needed to confirm these observations.

\section{DISCUSSION}

In this study, we describe the geographic distribution, host range, and phylogenetic position of $59 R$. solanacearum strains associated with potato bacterial wilt symptoms in Iran. Field surveys in two consecutive years (2017 to 2018) showed that potato bacterial wilt occurs across six provinces in the major potato-growing areas in Central, Western, Southwestern, and Southern Iran. Ninety-five percent of the strains isolated from potato in Iran (56 out of 59) were aggressively pathogenic on all the tested solanaceous plant species (eggplant, red nightshade, pepper, potato, and tomato) while three strains were hypovirulent on potato and tomato plants. Both specific PCR assays and phylogenetic analyses demonstrated that nearly all the strains isolated in Iran were members of phylotype IIB/sequevar I of the RSSC, while the strain Sh16 was assigned to IIB/sequevar 25 , which also called biovar $2 \mathrm{~T}$.

The IIB/1 = R3B2 strains of $R$. solanacearum, which are known as potato brown rot ecotype, cause wilting on potato, tomato, eggplant, pepper, and geranium and are adapted to the geographic regions characterized with a cool climate, which are often at high altitude (Parkinson et al. 2013; Wicker et al. 2012). Potato brown rot ecotype (IIB/1) likely originated from the Brazilian Amazon basin (Wicker et al. 2012). Since the early 16th century, when the solanaceous annual crops were introduced from South America to the Europe by Spanish conquistadors, the pathogen has been distributed around the globe along with the infected plant materials (Clarke et al. 2015; Gutarra et al. 2017; Santiago et al. 2017; Wicker et al. 2012). We have demonstrated that brown rot-inducing 
populations of $R$. solanacearum in Iran, while poorly polymorphic, are phylogenetically close to the IIB-1 strains collected in different countries from Europe, Africa, South America, and even Asia. This finding could be due in part to the relatively low number of reference strains included in our investigations, as well as to the long-lasting presence of the pathogen in the country. Indeed, considering the relatively long history of potato cultivation in Iran which has been introduced from the East India Company's territories in India in the early 18th century (even earlier than the introduction of the crop into Africa), it could be hypothesized that

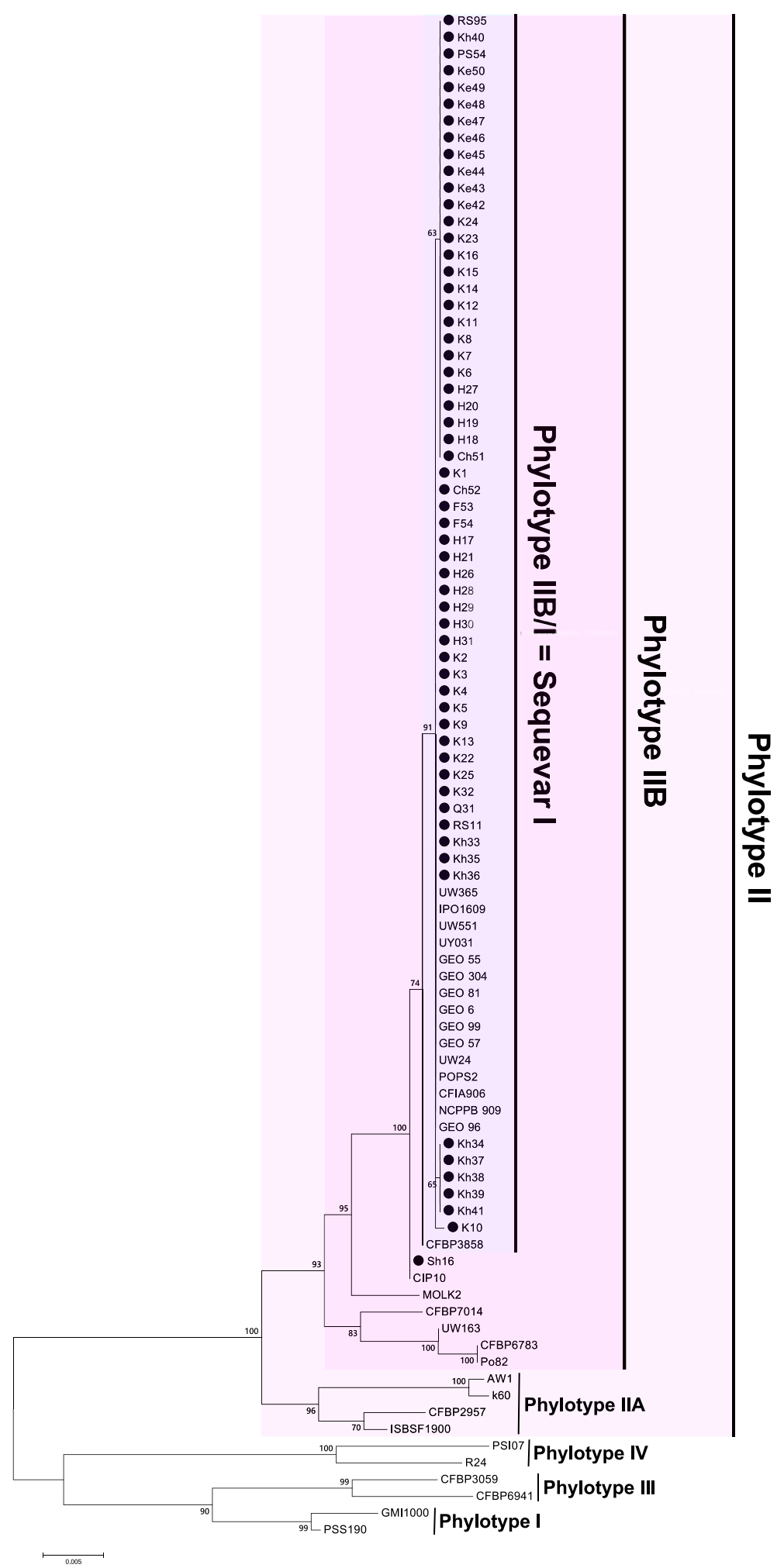

Fig. 2. Maximum likelihood phylogeny of Ralstonia solanacearum strains isolated in Iran based on the concatenated sequences of three chromosomal housekeeping genes $(g y r B, m u t S$, and $r p l B)$ and two megaplasmid virulence-associated genes $(e g l$ and $f l i C)$ generated using Tamura-Nei model $+\mathrm{Gamma}$ distributed method. The bar presents number of substitutions per site. Among the 59 Iranian strains, 58 strains were identified as phylotype IIB/sequevar 1 (IIB/I) lineage of the $R$. solanacearum species complex. The atypical strain Sh16, which was isolated from potato in Khuzestan province, was confirmed as biovar $2 \mathrm{~T}$ and phylotype IIB/sequevar 25. Pale blue background indicates phylotype IIB/sequevar 1 (IIB/I) strains, while pink and pale pink backgrounds indicate phylotype IIB and phylotype II clades, respectively. 
the bacterial wilt pathogen has also been established in Iran for a long period of time. Although it has been proposed that the IIB/1 strains of the pathogen are homogeneous across the globe, intrapopulation genetic diversity was reported for the potato brown rot ecotype strains isolated in different geographic areas using MLSAbased investigation. For instance, Castillo and Greenberg (2007) showed that the Asian sequevar I strains were scattered into different sequence types. Furthermore, MLSA-based phylogenetic studies revealed high genetic diversity of RSSC, including IIB/1 strains, in India as well as several Indian Ocean islands (Sakthivel et al. 2016; Yahiaoui et al. 2017). Similar results were obtained in Iran, providing novel insight into the global diversity of potato brown rot ecotype of the pathogen. Further comparative genomics and molecular-phylogenetic investigations will elucidate the evolutionary forces shaping the genetic diversity of this lineage in a global scale.

Although the potato brown rot ecotype was isolated in different provinces of Iran with various climatic conditions, the disease was more prevalent in Kurdistan and Hamadan provinces where potatogrowing areas located in high plains with cool springs and summers. However, the pathogen has also been frequently isolated in the Southern (Kerman) and Southwestern (Khuzestan) provinces which have temperate and hot summers. In both the later areas, potato is planted during the winter months (November to April) when the climatic conditions is similar to that observed in the high plains of western provinces of the country. Huerta et al. (2015) evaluated the effect of temperature adaptation on the competitive fitness of $R$. solanacearum strains. They found that adaptation to cool temperatures enables R3B2 strains to prevail in tropical highlands. These observations are in congruence with the adaptation of the potato brown rot ecotype to cool-climate as described elsewhere (Parkinson et al. 2013; Wicker et al. 2012). Our study also identified some geographical structure in the Iranian brown rot populations that should be investigated further. The Khuzestan province, characterized by its low altitudes and its hot climatic conditions, seems to harbor original STs (ST3 and ST6) (Fig. 3) that should be further studied.

Clustered or aggregated dispersal pattern of bacterial wilt disease in Iran indicates patchy distribution of diseased fields, characteristic of seedborne pathogens (Madden et al. 2007). Results obtained in this study were in congruence with those of bacterial spot of tomato and pepper in the country (Osdaghi et al. 2017). This pattern of dispersion suggests the importance of infected planting materials (latently infected tubers) as the primary source of inoculum. These findings are being reflected in potato tuber production and transportation pattern in the country. Indeed, most of the potato tubers used as planting materials in Iran are produced in Hamadan and Kurdistan provinces where present a significant part of the genetic diversity of $R$. solanacearum. Uninspected tuber transportation from western provinces to the areas with no history of the disease could be considered as one of the leading forces in the widespread distribution of the bacterial wilt pathogen in Iran. Uninspected intranational transportation of planting materials in Iran have also led to the current expansion of other economically important quarantine diseases including bacterial leaf spot of tomato and pepper, bacterial wilt of dry beans caused by Curtobacterium flaccumfaciens pv. flaccumfaciens (Osdaghi et al. 2018b), common bacterial blight of beans caused by X. axonopodis pv. phaseoli (Osdaghi et al. 2010), and bacterial leaf spot of alfalfa caused by X. euvesicatoria pv. alfalfae (Yaripour et al. 2018). Moreover, because there are other important potato-growing areas other than Hamadan and Kurdistan provinces, there is a concern from growers and phytosanitary authorities on further distribution of the pathogen into the areas with no bacterial wilt incidence. This suggests that there is an urgent need to reduce risks of bacterial wilt epidemics across the country which otherwise may negatively affect potato industry in Iran. Therefore, development and adoption of strict phytosanitary measures, including quarantine procedures, are needed to prevent further spread and establishment of the bacterial wilt pathogen in Iran.

In conclusion, results of the present study provide a comprehensive overview into the geographic distribution, population diversity and taxonomic position of the bacterial wilt pathogen infecting potato plants in Iran. Our analyses revealed that $R$. solanacearum strains causing bacterial wilt in Iran are nearly homogeneous in terms of phylogenetic relationships and taxonomic status, while attenuated pathogenicity was observed in a small fraction of the

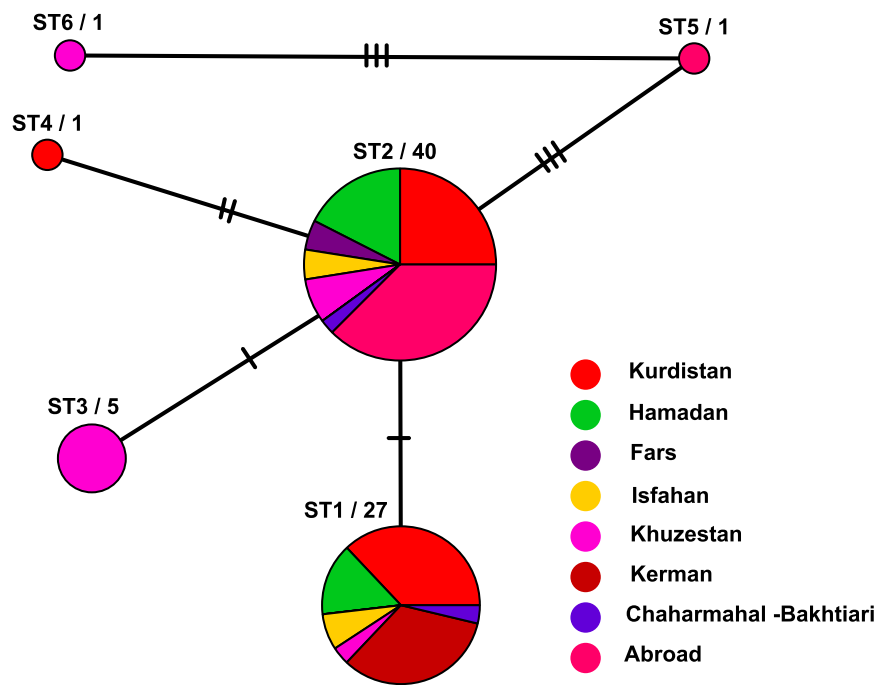

Fig. 3. TCS sequence type (ST) network generated using the POPArt program from the concatenated partial sequences of three chromosomal housekeeping genes $($ gyrB,$m u t S$, and $r p l B)$ and two megaplasmid virulence-associated genes ( $\mathrm{gl}$ and $\mathrm{fliC}$ ) in Ralstonia solanacearum strains isolated in Iran. The size of the circles indicates the relative frequency of sequences belonging to a particular ST. Hatch marks along the branches indicate the number of mutations (single nucleotide polymorphisms). Each color indicates one of the seven provinces where the bacterial strains were isolated, while the strains retrieved from GenBank are assigned Abroad. The numbers on the left of the radix character represent the ST assignment according to Table 1, while the numbers on the right of the radix character indicate the number of strains in a given ST.

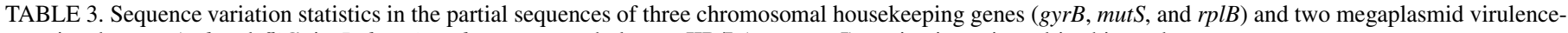
associated genes $(\mathrm{egl}$ and $\mathrm{fliC}$ ) in Ralstonia solanacearum phylotype IIB/I (sequevar I) strains investigated in this study

\begin{tabular}{|c|c|c|c|c|c|c|c|c|c|c|c|c|c|}
\hline \multirow[b]{2}{*}{ Gene } & \multirow{2}{*}{$\begin{array}{c}\text { Number } \\
\text { of } \\
\text { strains }\end{array}$} & \multirow{2}{*}{$\begin{array}{c}\text { Number } \\
\text { of } \\
\text { nucleotides }\end{array}$} & \multirow{2}{*}{$\begin{array}{c}\text { Number } \\
\text { of } \\
\text { alleles }\end{array}$} & \multirow[b]{2}{*}{$\begin{array}{l}\text { Allele } \\
\text { frequency }\end{array}$} & \multirow{2}{*}{$\begin{array}{l}\text { Number of } \\
\text { segregating } \\
\text { sites }\end{array}$} & \multirow{2}{*}{$\begin{array}{c}\% \text { of } \\
\text { polymorphic } \\
\text { sites }\end{array}$} & \multirow[b]{2}{*}{$\begin{array}{l}\text { Nucleotide } \\
\text { diversity }(\pi)\end{array}$} & \multirow{2}{*}{$\begin{array}{c}\text { Number } \\
\text { of } \\
\text { mutations } \\
(\eta)\end{array}$} & \multirow[b]{2}{*}{$\begin{array}{c}\text { Allele } \\
\text { diversity }\end{array}$} & \multicolumn{3}{|c|}{$\begin{array}{l}\text { Value for indicated } \\
\text { neutrality test }\end{array}$} & \multirow{2}{*}{$\begin{array}{c}\text { Minimum } \\
\text { number of } \\
\text { recombinatior } \\
\text { events }\end{array}$} \\
\hline & & & & & & & & & & Tajima's $D$ & $\begin{array}{l}\text { Fu and } \\
\text { Li's D* }\end{array}$ & $\mathrm{Fu}$ and Li's $\mathrm{F}^{*}$ & \\
\hline Concatenated & 74 & 2,938 & 5 & 0.067 & 7 & 0.238 & $0.025 \times 10^{-2}$ & 7 & 0.578 & NS, $0.025 \times 10^{-2}$ & $-2.958 *$ & $-2.805^{*}$ & 0 \\
\hline$e g l$ & 74 & 665 & 1 & 0.013 & 0 & 0.150 & 0.000 & 0 & 0.000 & NA & NA & NA & NA \\
\hline $\mathrm{fliC}$ & 74 & 315 & 1 & 0.013 & 0 & 0.317 & 0.000 & 0 & 0.000 & NA & $\mathrm{NA}$ & NA & NA \\
\hline $\operatorname{gyr} B$ & 74 & 695 & 3 & 0.040 & 3 & 0.431 & $0.075 \times 10^{-2}$ & 3 & 0.487 & NS, $0.075 \times 10^{-2}$ & NS, -1.882 & $\mathrm{NS},-1.621$ & 0 \\
\hline mutS & 74 & 614 & 3 & 0.040 & 3 & 0.488 & $0.013 \times 10^{-2}$ & 3 & 0.054 & NS, $0.013 \times 10^{-2}$ & $-3.250 *$ & $-3.220 * *$ & 0 \\
\hline$r p l B$ & 74 & 649 & 2 & 0.027 & 1 & 0.154 & $0.020 \times 10^{-2}$ & 1 & 0.128 & $\mathrm{NS},-0.461$ & NS, -0.461 & NS, 0.261 & 0 \\
\hline
\end{tabular}

a Allele frequency shows number of alleles/number of strains. NS, not significant; NA, not applicable; *, $P<0.05$; and **, $P \leq 0.01$. 
strains. Nonpathogenic strains of the pathogen often have abnormal colony morphology which accompanied with the efpR-dependent phenotypic conversion that could occur in natural conditions (Perrier et al. 2019). Further investigations would shed light on the hypovirulent nature of the three strains isolated in this study. The data presented in this study thus expands the current knowledge on IIB-1 global diversity. Furthermore, considering the Iran scale, several STs were shared among the geographically distant areas, indicating intranational dissemination of the pathogen more probably via latently infected potato tubers. These observations highlight the importance of quarantine inspection at the borders and at the intranational scales to prevent introduction of new genotypes of the pathogen and to prevent bacterial wilt outbreaks in the areas with no history of the disease. Finally, the unique phylogenetic position of the Iranian $R$. solanacearum strains advocate a need for further in-depth investigation to develop resistance screening and breeding programs against the current status of the bacterial wilt pathogen in the country.

Data availability. The data that support the findings of this study are available in the NCBI GenBank database.

\section{ACKNOWLEDGMENTS}

We thank Stephane Poussier (Ph.D.) (University of La Réunion, SaintDenis, Reunion) for providing the reference strain UW365. N. Sedighian and E. Osdaghi benefited from the sabbatical interactions promoted and supported by funding from Ministry of Science, Research and Technology, Iran.

\section{LITERATURE CITED}

Ansari, M., Taghavi, S. M., Hamzehzarghani, H., Valenzuela, M., Siri, M. I., and Osdaghi, E. 2019. Multiple introductions of tomato pathogen Clavibacter michiganensis subsp. michiganensis into Iran as revealed by a global-scale phylogeographic analysis. Appl. Environ. Microbiol. 85:e02098-e19.

Benson, D. A., Cavanaugh, M., Clark, K., Karsch-Mizrachi, I., Lipman, D. J., Ostell, J., and Sayers, E. W. 2017. GenBank. Nucleic Acids Res. 45:D37-D42.

Buddenhagen, I., Sequeira, L., and Kelman, A. 1962. Designation of races in Pseudomonas solanacearum. Phytopathology 52:726.

Castillo, J. A., and Greenberg, J. T. 2007. Evolutionary dynamics of Ralstonia solanacearum. Appl. Environ. Microbiol. 73:1225-1238.

Cellier, G., and Prior, P. 2010. Deciphering phenotypic diversity of Ralstonia solanacearum strains pathogenic to potato. Phytopathology 100: 1250-1261.

Champoiseau, P. G., Jones, J. B., and Allen, C. 2009. Ralstonia solanacearum race 3 biovar 2 causes tropical losses and temperate anxieties. Plant Health Prog. 10:35.

Clarke, C. R., Studholme, D. J., Hayes, B., Runde, B., Weisberg, A., Cai, R., Wroblewski, T., Daunay, M.-C., Wicker, E., Castilo, J. A., and Vinatzer, B. A. 2015. Genome-enabled phylogeographic investigation of the quarantine pathogen Ralstonia solanacearum race 3 biovar 2 and screening for sources of resistance against its core effectors. Phytopathology 105: 597-607.

Clement, M., Snell, Q., Walker, P., Posada, D., and Crandall, K. 2002. TCS: Estimating gene genealogies. International Proceedings of Parallel and Distributed Processing Symposium 2:184.

Coupat-Goutaland, B., Bernillon, D., Guidot, A., Prior, P., Nesme, X., and Bertolla, F. 2011. Ralstonia solanacearum virulence increased following large interstrain gene transfers by natural transformation. Mol. PlantMicrobe Interact. 24:497-505.

Danesh, D., and Bahar, M. 1984. Occurrence of bacterial wilt of potato in Iran. Pages 407-408 in: Proceedings of the Ninth Triennial Conference of the European Association for Potato Research, Interlaken, Switzerland.

Elphinstone, J. G. 2005. The current bacterial wilt situation: global overview. Pages 9-28 in: Bacterial Wilt Diseases and the Ralstonia solanacearum Species Complex. C. Allen, P. Prior, and A. C. Hayward, eds. American Phytopathological Society, St. Paul, MN.

EPPO. 2018. PM 7/21 (2) Ralstonia solanacearum, R. pseudosolanacearum and $R$. syzygii (Ralstonia solanacearum species complex). Bull. OEPP/ EPPO Bull. 48:32-63.

FAOSTAT. 2018. Food and Agriculture Organization of the United Nations, FAOSTAT database.

Fegan, M., Holoway, G., Hayward, A. C., and Timmis, J. 1998. Development of a diagnostic test based on the polymerase chain reaction (PCR) to identify strains of $R$. solanacearum exhibiting the biovar 2 genotype. Pages 34-43 in: Bacterial Wilt Disease: Molecular and Ecological Aspects. P. Prior, C. Allen, and J. Elphinstone, eds. Springer, Berlin.

Fegan, M., and Prior, P. 2005. How complex is the Ralstonia solanacearum species complex. Pages 449-462 in: Bacterial Wilt Disease and the Ralstonia solanacearum Species Complex. C. Allen, P. Prior, and A. C. Hayward, eds. American Phytopathological Society, St. Paul, MN.

Gurjar, M. S., Sagar, V., Bag, T. K., Singh, B. P., Sharma, S., Jeevalatha, A., et al. 2015. Genetic diversity of Ralstonia solanacearum strains causing bacterial wilt of potato in the Meghalaya State of India. J. Plant Pathol. 97: 135-142.

Gutarra, L., Herrera, J., Fernandez, E., Kreuze, J., and Lindqvist-Kreuze, H. 2017. Diversity, pathogenicity and current occurrence of bacterial wilt bacterium Ralstonia solanacearum in Peru. Front. Plant Sci. 8:1221.

Hayward, A. C. 1994. The hosts of Pseudomonas solanacearum. Pages 9-24 in: Bacterial Wilt: The Disease and Its Causative Agent, Pseudomonas solanacearum. A. C. Hayward and G. L. Hartman, eds. CAB International, Wallingford, U.K.

Hong, J. C., Norman, D. J., Reed, D. L., Momol, M. T., and Jones, J. B. 2012. Diversity among Ralstonia solanacearum strains isolated from the southeastern United States. Phytopathology 102:924-936.

Huerta, A. I., Milling, A., and Allen, C. 2015. Tropical strains of Ralstonia solanacearum outcompete race 3 biovar 2 strains at lowland tropical temperatures. Appl. Environ. Microbiol. 81:3542-3551.

Huson, D. H., and Bryant, D. 2006. Application of phylogenetic networks in evolutionary studies. Mol. Biol. Evol. 23:254-267.

Izadiyan, M., and Taghavi, S. M. 2011. Genotypic diversity of Iranian strains of Ralstonia solanacearum. Phytopathol. Mediterr. 50:236-244.

Jones, J. B., Zitter, T. A., Momol, T. M., and Miller, S. A. 2016. Compendium of Tomato Diseases and Pests. 2nd ed. American Phytopathological Society, St. Paul, MN

Katoh, K., Rozewicki, J., and Yamada, K. D. 2019. MAFFT online service: Multiple sequence alignment, interactive sequence choice and visualization. Brief. Bioinform. 20:1160-1166.

Kelman, A. 1954. The relationship of pathogenicity in Pseudomonas solanacearum to colony appearance on a tetrazolium medium. Phytopathology 44:693-695.

Kumar, S., Stecher, G., and Tamura, K. 2016. MEGA7: Molecular evolutionary genetics analysis version. 7.0 for bigger datasets. Mol. Biol. Evol. 33:1870-1874.

Leigh, J. W., and Bryant, D. 2015. popart: Full-feature software for haplotype network construction. Methods Ecol. Evol. 6:1110-1116.

Librado, P., and Rozas, J. 2009. DnaSP v5: A software for comprehensive analysis of DNA polymorphism data. Bioinformatics 25:1451-1452.

Madden, L. V., Hughes, G., and van den Bosch, F. 2007. The Study of Plant Disease Epidemics. American Phytopathological Society, St. Paul, MN.

Mahbou Somo Toukam, G., Cellier, G., Wicker, E., Guilbaud, C., Kahane, R., Allen, C., and Prior, P. 2009. Broad diversity of Ralstonia solanacearum strains in Cameroon. Plant Dis. 93:1123-1130.

Martin, D. P., Murrell, B., Golden, M., Khoosal, A., and Muhire, B. 2015. RDP4: Detection and analysis of recombination patterns in virus genomes. Virus Evol. 1:vev003.

Nouri, S., Bahar, M., and Fegan, M. 2009. Diversity of Ralstonia solanacearum causing potato bacterial wilt in Iran and the first record of phylotype II/biovar 2T strains outside South America. Plant Pathol. 58:243-249.

Opina, N., Tavner, F., Hollway, G., Wang, J.-F., Li, T.-H., Maghirang, R., Fegan, M., Hayward, A. C., Krishnapillai, V., Hong, W. F., Holloway, B. W., and Timmis, J. 1997. A novel method for development of species and strain-specific DNA probes and PCR primers for identifying Burkholderia solanacearum (formerly Pseudomonas solanacearum). Asia Pac. J. Mol. Biol. Biotechnol. 5:19-30.

Osdaghi, E., Ansari, M., Taghavi, S. M., Zarei, S., Koebnik, R., and Lamichhane, J. R. 2018a. Pathogenicity and phylogenetic analysis of Clavibacter michiganensis strains associated with tomato plants in Iran. Plant Pathol. 67:957-970.

Osdaghi, E., Shams-Bakhsh, M., Alizadeh, A., and Lak, M. R. 2010. Study on common bean seed lots for contamination with Xanthomonas axonopodis pv. phaseoli by BIO-PCR technique. Int. J. Agr. Technol 6:503-513.

Osdaghi, E., Taghavi, S. M., Calamai, S., Biancalani, C., Cerboneschi, M., Tegli, S., and Harveson, R. M. 2018b. Phenotypic and molecular-phylogenetic analysis provide novel insights into the diversity of Curtobacterium flaccumfaciens. Phytopathology 108:1154-1164.

Osdaghi, E., Taghavi, S. M., Hamzehzarghani, H., Fazliarab, A., Harveson, R. M., Tegli, S., and Lamichhane, J. R. R. 2018c. Epiphytic Curtobacterium flaccumfaciens strains isolated from symptomless solanaceous vegetables are pathogenic on leguminous but not on solanaceous plants. Plant Pathol. 67:388-398.

Osdaghi, E., Taghavi, S. M., Hamzehzarghani, H., Fazliarab, A., and Lamichhane, J. R. 2017. Monitoring the occurrence of tomato bacterial spot 
and range of the causal agent Xanthomonas perforans in Iran. Plant Pathol. 66:990-1002.

Osdaghi, E., Taghavi, S. M., Hamzehzarghani, H., and Lamichhane, J. R. 2016. Occurrence and characterization of the bacterial spot pathogen Xanthomonas euvesicatoria on pepper in Iran. J. Phytopathol. 164: $722-734$.

Parkinson, N., Bryant, R., Bew, J., Conyers, C., Stones, R., Alcock, M., et al. 2013. Application of variable-number tandem-repeat typing to discriminate Ralstonia solanacearum strains associated with English watercourses and disease outbreaks. Appl. Environ. Microbiol. 79: 6016-6022.

Perrier, A., Barlet, X., Rengel, D., Prior, P., Poussier, S., Genin, S., et al. 2019. Spontaneous mutations in a regulatory gene induce phenotypic heterogeneity and adaptation of Ralstonia solanacearum to changing environments. Environ. Microbiol. 21:3140-3152.

Poussier, S., Prior, P., Luisetti, J., Hayward, C., and Fegan, M. 2000b. Partial sequencing of the $h r p B$ and endoglucanase genes confirms and expands the known diversity within the Ralstonia solanacearum species complex. Syst. Appl. Microbiol. 23:479-486.

Poussier, S., Trigalet-Demery, D., Vandewalle, P., Goffinet, B., Luisetti, J., and Trigalet, A. 2000a. Genetic diversity of Ralstonia solanacearum as assessed by PCR-RFLP of the hrp gene region, AFLP and 16S rRNA sequence analysis and identification of an African subdivision. Microbiology 146: 1679-1692.

Prior, P., Ailloud, F., Dalsing, B. L., Remenant, B., Sanchez, B., and Allen, C. 2016. Genomic and proteomic evidence supporting the division of the plant pathogen Ralstonia solanacearum into three species. BMC Genomics 17:90.

Ravelomanantsoa, S., Vernière, C., Rieux, A., Costet, L., Chiroleu, F., Arribat, S., et al. 2018. Molecular epidemiology of bacterial wilt in the Madagascar highlands caused by Andean (phylotype IIB-1) and African (phylotype III) brown rot strains of the Ralstonia solanacearum species complex. Front. Plant Sci. 8:2258.

Safni, I., Cleenwerck, I., De Vos, P., Fegan, M., Sly, L., and Kappler, U. 2014. Polyphasic taxonomic revision of the Ralstonia solanacearum species complex: Proposal to emend the descriptions of Ralstonia solanacearum and Ralstonia syzygii and reclassify current $R$. syzygii strains as Ralstonia syzygii subsp. syzygii subsp. nov., $R$. solanacearum phylotype IV strains as Ralstonia syzygii subsp. indonesiensis subsp. nov., banana blood disease bacterium strains as Ralstonia syzygii subsp. celebesensis subsp. nov. and
$R$. solanacearum phylotype I and III strains as Ralstonia pseudosolanacearum sp. nov. Int. J. Syst. Evol. Microbiol. 64:3087-3103.

Sagar, V., Jeevalatha, A., Mian, S., Chakrabarti, S. K., Gurjar, M. S., Arora, R. K., Sharma, S., Bakade, R. R., and Singh, B. P. 2014. Potato bacterial wilt in India caused by strains of phylotype I, II and IV of Ralstonia solanacearum. Eur. J. Plant Pathol. 138:51-65.

Sakthivel, K., Gautam, R., Kumar, K., Dam Roy, S., Kumar, A., Devendrakumar, C., Vibhuti, M., Neelan, S., and Vinatzer, B. A. 2016. Diversity of Ralstonia solanacearum strains on the Andaman Islands in India. Plant Dis. 100:732-738.

Santiago, T., Lopes, C., Caetano-Anollés, G., and Mizubuti, E. 2017. Phylotype and sequevar variability of Ralstonia solanacearum in Brazil, an ancient center of diversity of the pathogen. Plant Pathol. 66:383-392.

Schonfeld, J., Heuer, H., van Elsas, J. D., and Small, K. 2003. Specific and sensitive detection of Ralstonia solanacearum in soil on the basis of PCR amplification of $\mathrm{fliC}$ fragments. Appl. Environ. Microbiol. 69: 7248-7256.

Sedighian, N., Krijger, M., Taparia, T., Taghavi, S. M., Wicker, E., van der Wolf, J. M., and Osdaghi, E. 2020. Genome Resource of Two Potato Strains of Ralstonia solanacearum Biovar 2 (Phylotype IIB/sequevar 1) and Biovar 2T (Phylotype IIB/Sequevar 25) Isolated from lowlands in Iran. Mol. Plant-Microbe Interact. doi.org/10.1094/MPMI-02-20-0026-A

Smith, E. F. 1896. A bacterial disease of the tomato, eggplant and Irish potato (Bacillus solanacearum nov. sp.). U.S. Department of Agriculture, Washington, D.C.

van der Wolf, J. M., and De Boer, S. H. 2007. Bacterial pathogens of potato. Pages 595-617 in: Potato Biology and Biotechnology. Elsevier, New York.

Wale, S., Platt, B., and Cattlin, N. D. 2008. Diseases, Pests and Disorders of Potatoes: A Colour Handbook. CRC Press, Boca Raton, FL.

Wicker, E., Lefeuvre, P., Cambiaire, J. C., Lemaire, C., Poussier, S., and Prior, P. 2012. Contrasting recombination patterns and demographic histories of the plant pathogen Ralstonia solanacearum inferred from MLSA. ISME J. 6:961-974.

Yahiaoui, N., Chéron, J.-J., Ravelomanantsoa, S., Hamza, A. A., Petrousse, B., Jeetah, R., et al. 2017. Genetic diversity of the Ralstonia solanacearum species complex in the Southwest Indian Ocean Islands. Front. Plant Sci. 8:2139.

Yaripour, Z., Taghavi, S. M., Osdaghi, E., and Lamichhane, J. R. 2018. Host range and phylogenetic analysis of Xanthomonas alfalfae causing bacterial leaf spot of alfalfa in Iran. Eur. J. Plant Pathol. 150:267-274. 